\title{
Pobreza multidimensional: Um estudo de caso das privações básicas na região nordeste de Santa Maria/RS
}

\author{
Multidimensional poverty: a case study of basic deprivation in the northeast region of Santa \\ Maria/RS
}

\section{Cristiéle de Almeida Vieira', Diogo Alberto de Moraes" ${ }^{\mathrm{II}}$, Caroline Lucion Puchale ${ }^{\mathrm{III}}$, Bianca Uberti ${ }^{\mathrm{IV}}$, Sibele Vasconcelos de Oliveira ${ }^{\mathrm{V}}$ e Solange Regina Marin ${ }^{\mathrm{VI}}$}

\begin{abstract}
RESUMO
Amartya Sen (2000) define pobreza como uma situação de precariedade em diferentes aspectos da vida. Ou seja, ao invés de considerar apenas a renda familiar, a pobreza analisada em perspectiva multidimensional prima pela identificação das privações do indivíduo, seja no âmbito social, econômico ou político. A problemática que permeia este trabalho é: Quão pobres são os indivíduos da região nordeste do município de Santa Maria (RS) quando consideradas suas capacitações básicas (Saúde, Alimentação, Educação e Habitação e Saneamento Básico)? O objetivo principal é identificar as dimensões de maiores privações dos indivíduos do referido município, a fim de auxiliar na formulação de políticas públicas. Esta é uma pesquisa descritiva das informações coletadas entre 2015 e 2016 na região nordeste de Santa Maria (RS), com aplicação de 565 questionários. Como resultado geral, tem-se que os residentes da região nordeste santa-mariense possuem um baixo nível de pobreza multidimensional, porém com alguns indícios de privação nas condições de alimentação.
\end{abstract}

Palavras- chaves: Pobreza Multidimensional; Amartya Sen; Santa Maria/RS

\section{ABSTRACT}

Amartya Sen (2000) descrive poverty what a situation of precariousness in many aspects of life. In other words, it isn't considered only income but the poverty in a multidimensional perspective identifies the indivual deprivation in social, economic and political scope. The problem this article is: How poor be the individuals the northeast region the municipal of Santa Maria/RS when analyzed the yours capacitações basics (Health, Feeding, Education and Housing and Basic Habitation)? The search objective is identify the dimensions of more privations the individuals this region. This is research descriptive the collected information between 2015 and 2016 in northeast region of Santa Maria/RS, with aplication the 565 search forms. The overall result is that the individuals the northeast region have low multidimensional poverty, but with some indications the privation in alimentation dimension.

Keywords: Multidimensional Poverty; Amartya Sen; Santa Maria/RS

\footnotetext{
${ }^{I}$ Mestranda em Economia pela Universidade Estadual de Maringá. E-mail: crissavieira@gmail.com

IIAcadêmico de Ciências Econômicas pela Universidade Federal de Santa MariaRS, Brasil. E-mail: diogomoraes_idp@yahoo.com. br

IIIAcadêmico de Ciências Econômicas pela Universidade Federal de Santa MariaRS, Brasil. E-mail:_bianca.ubertii@gmail.com Iv Mestranda em Economia e Desenvolvimento pela Universidade Federal de Santa MariaRS, Brasil. E-mail: carol.puchale@ gmail.com

vProfessora do Departamento de Economia e Relações Internacionais da Universidade Federal de Santa Maria. RS, Brasil.

E-mail: sibele_oliveira@yahoo.com.br

VIProfessora do Departamento de Economia e Relações Internacionais da Universidade Federal de Santa Catarina.SC, Brasil.

E-mail: solremar@yahoo.com.br
} 


\section{Introdução}

A pobreza multidimensional é uma extensão do modelo tradicional de avaliação da pobreza, em que apenas considera-se a renda monetária como variável determinante do grau de privação dos indivíduos. Esta nova definição engloba os diferentes tipos de privações dos indivíduos em seu âmbito social, econômico e político. Amartya Sen (1997; 2010), em sua obra sobre a abordagem das capacitações, afirma que o processo de expansão das liberdades é elemento fundamental para a redução da pobreza.

Esta ausência de liberdades vai além da pobreza econômica, abarca também a pobreza política, social, de carência de serviços públicos e assistência social. Para Sen (2010), a ausência de liberdades substanciais pode relacionar-se tanto com a pobreza econômica quanto com a escassez de programas epidemiológicos, isto é, com a inexistência de um sistema bem planejado de assistência médica e educacional e com instituições eficazes para a manutenção da paz e da ordem locais. Citam-se ainda as privações derivadas da violação às liberdades, resultantes diretamente de uma negação de liberdades políticas e civis (SEN, 2010, p.17).

Santa Maria é um município localizado na região central do estado do Rio Grande do Sul, com extensão territorial de $1.788,12$ km² e população de 261.031 habitantes; sendo 123.634 homens e 137.397 mulheres (IBGE, 2010). A cidade é composta por 41 bairros e entre os 9 maiores bairros encontram-se: Camobi, Centro, Juscelino Kubitschek, Nova Santa Marta, Tancredo Neves, Pinheiro Machado, Salgado Filho, Nossa Senhora Medianeira e Urlândia. Ressalta-se também, que dentro destes 9 maiores bairros residem cerca de 50,14\% da população total (ADSM, 2017). Apesar de ser reconhecida regionalmente como 'cidade cultura', pela presença de várias instituições educacionais, incluindo as ofertantes de ensino superior, Santa Maria apresenta problemas socioeconômicos de diversas ordens. Em especial, cita-se a incidência de pobreza, que conforme dados do IBGE (2000), afligem 25,26\% dos habitantes do município.

Ressalta-se, que o presente trabalho, possui como objeto de estudo a região nordeste de Santa Maria/RS, que é composta por 6 bairros, sendo eles: Campestre do Menino Deus, Itararé, KM 3, Menino Jesus, Nossa Senhora das Dores e Presidente João Goulart. Esta região foi escolhida pois, abrange o menor bairro da cidade, que é o KM 3, como também agrega áreas urbanas e rurais, demonstrado ser uma região bastante diversa quanto o espaço de pesquisa.

Dentro desta perspectiva, a problemática que permeia este estudo é: Quão pobres são os indivíduos da região nordeste do município de Santa Maria (RS) quando consideradas suas capacitações básicas (Saúde, Alimentação, Educação e Habitação e Saneamento Básico)? O objetivo central é identificar as dimensões de maiores privações a fim de auxiliar na formulação e implementação de políticas públicas.

O artigo subdivide-se em cinco seções. Após esta introdução é apresentado o conceito de pobreza multidimensional a partir dos preceitos teóricos de Amartya Sen. Na seção três, são descritos os aspectos metodológicos da pesquisa, em sequência, a análise dos resultados. Na última seção, encontram-se as considerações finais do trabalho.

\section{Pobreza multidimensional}

Amartya Sen (2000) define pobreza como uma situação de precariedade em diferentes aspectos da vida de um indivíduo. Ao invés de considerar, simplesmente, a renda familiar baixa, ignorando outros elementos pertinentes ao bem-estar, a teoria da pobreza multidimensional prima pela identificação das privações do indivíduo ou da família.

A pobreza multidimensional está estruturada sobre conceitos como o de "privações", "funcionamentos" e "capacitações" (SEN, 2000). Um funcionamento é aquilo que uma pessoa realiza dentro de uma situação onde lhe é possível, por exemplo, estudar. Já uma capacitação é um conjunto de funcionamentos que a pessoa pode realizar, isto é, quando tal estudo é possível, efetivamente. Segundo Crespo e Gurovitz (2002, p. 5), as capacitações são "combinações alternativas de funcionamentos de possível realização" ou a "liberdade substantiva de realizar combinações alternativas de funcionamentos". Portanto, comer é um funcionamento, e a possibilidade de comer é uma capacitação. Sendo assim. a diferença entre o homem que faz jejum por vontade própria e o que jejua por não dispor de alimentos, é que o primeiro tem a oportunidade (ou capacitação) parar alimentar-se ao passo que o segundo não tem.

Por fim, a privação é a manifestação da pobreza propriamente dita. Uma pessoa com um conjunto capacitário pequeno é aquela que está privada de realizar muitos dos funcionamentos. Seja por não dispor da renda adequada para adquirir bens e serviços básicos necessários a uma vida saudável e digna, ou por viver em uma região com infraestrutura precária. Na abordagem das capacitações, a pobreza passa a ser entendida sob uma perspectiva multidimensional, isso significa retirar o fator renda da posição de único determinante, e colocá-lo lado a lado com os demais aspectos da vida de um indivíduo, ou grupo. Ainda segundo Crespo e Gurovitz (2002, p. 6), essa perspectiva melhora o "entendimento da natureza e das causas da pobreza e privação" porque entende a renda como um simples meio de obtenção dos bens e serviços necessários a uma vida adequada. E, portanto, reforça a importância de prover aos indivíduos as melhorias capazes de atingir os fins adequados: a qualidade de vida e o bem-estar.

Amartya Sen (2000) encara o desenvolvimento como um processo de expansão das liberdades individuais. A pobreza e os 
regimes antidemocráticos, por exemplo, são empecilhos para tal expansão e, por esse motivo, devem ser erradicados. De acordo com Crespo e Gurovitz (2002), Sen define cinco tipos de liberdade instrumental: liberdades políticas, facilidades econômicas, oportunidades sociais, garantias de transparência e segurança protetora. O autor defende que a expansão dessas liberdades deve ser o objetivo de toda e qualquer política pública que vise ao desenvolvimento socioeconômico. Tais liberdades podem, ainda, reforçar umas às outras, quando promovidas por uma sociedade. Por exemplo, liberdades políticas podem auxiliar na promoção de segurança econômica, e garantir às pessoas a liberdade de explorar atividades econômicas de maneira adequada.

A definição adequada de capacitações ainda oferece espaço para debates, em virtude da grande variedade de privações às quais indivíduos e comunidades estão submetidos nos dias de hoje. As políticas adequadas para a expansão das liberdades substantivas, da mesma forma, ainda são objeto para análises mais intensivas. O que não se pode negar, no entanto, é a importância que tem a inserção desses dois conceitos no estudo da pobreza e do desenvolvimento.

A proposta de análise da pobreza como fenômeno multidimensional é um grande avanço na teoria econômica porque promove um aprofundamento na maneira como a pobreza é encarada pelos gestores públicos. E, também, por contribuir na identificação dos contextos onde essas políticas se mostram necessárias.

\section{Procedimentos metodológicos}

O objetivo da presente pesquisa é analisar as fontes de privação dos indivíduos residentes na região nordeste da cidade de Santa Maria (RS). Como demonstrado na figura 1, a cidade está localizada na região central do estado do Rio Grande do Sul e apresenta, segundo o censo de 2010 do IBGE, uma população de 261.031 habitantes.

Figura 1 - Localização da cidade de Santa Maria/RS

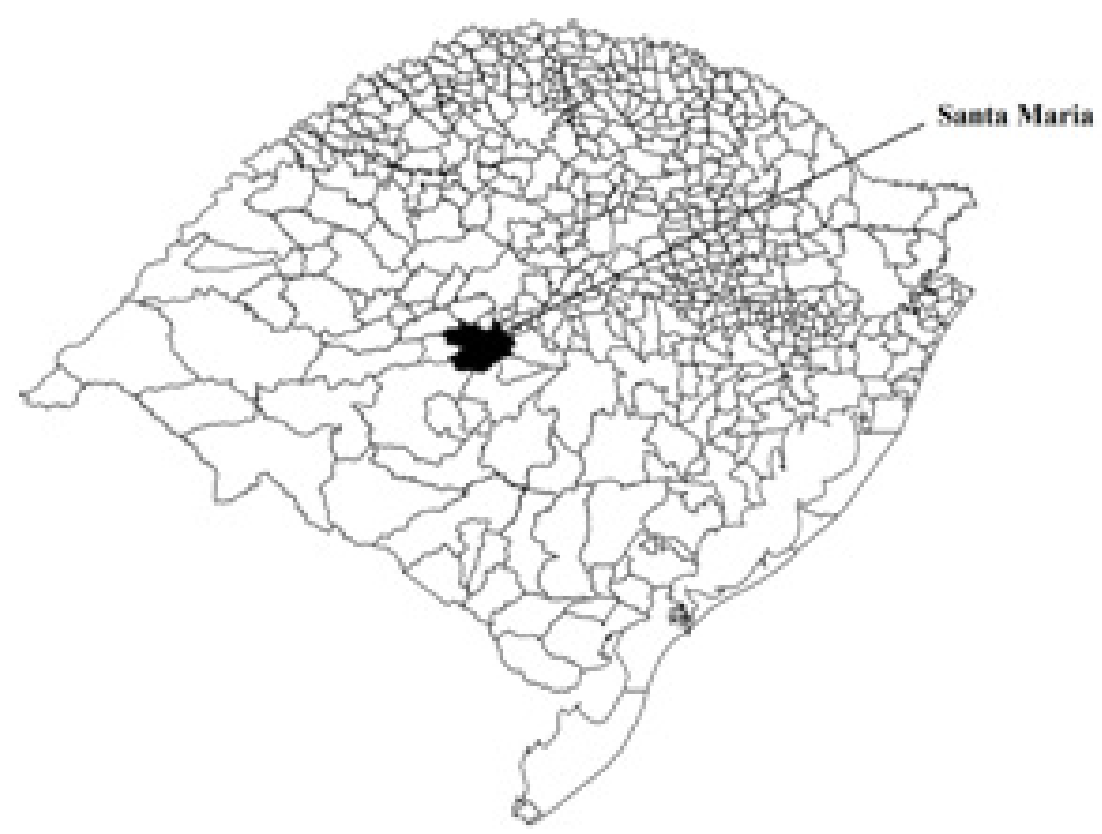

Fonte: elaboração própria a partir de IBGE

A presente cidade, alcançou em 2010 um IDHM (Índice de Desenvolvimento Humano municipal) superior à 0,78, índice considerado alto, conforme o Programa das Nações Unidas para o Desenvolvimento (PNUD). Contudo, o Índice de Incidência da Pobreza, que avalia a capacidade de consumo dos indivíduos - sendo que a pessoa é considerada pobre quando não tem acesso a uma cesta de bens considerada mínima para sua sobrevivência física - , para o município foi de 0,42 (limite inferior) e 0,45 (limite superior), assim, como tal índice varia entre 0 e 1, têm-se que a cidade encontra-se em uma situação intermediária entre a desigualdade nula e extrema. (IBGE, 2010) 
Para além da análise de dados secundários, este estudo operou com a coleta de dados primários que busca avaliar as características e percepções dos indivíduos em análise. Para tanto, a amostra foi de 565 indivíduos, considerando-se a população residente nos bairros - Campestre do Menino Deus, Menino Jesus, Itararé, Nossa Senhora das Dores, Km Três e Presidente João Goulart - situados na região nordeste da cidade de Santa Maria (RS). Estes bairros contam com uma população de 28.819 habitantes, o que representa $11,04 \%$ da população total da cidade de Santa Maria/RS.

Salienta-se que o grau de significância estatística utilizado para cálculo do tamanho da amostra foi de 95\% e a técnica empregada para coleta dos dados foi por conveniência. Ainda, a coleta de dados primários ocorreu entre os anos de 2015 e 2016.

Dentre as informações coletadas em campo, estão os componentes de diferentes dimensões da pobreza. Após pesquisa bibliográfica, as dimensões elencadas para análise foram: Saúde, Alimentação, Educação e Habitação e acesso aos Serviços Básicos, como pode ser observado no quadro 1.

Quadro 1 - Dimensões e perguntas componentes do instrumento de coleta de dados

\begin{tabular}{|c|c|}
\hline Dimensão & Perguntas realizadas \\
\hline Saúde & $\begin{array}{l}\text { 1. Peso e Altura (para ser gerado o Índice de Massa Corporal) } \\
\text { 2. Você tem acesso aos serviços de saúde (médico, dentista, farmácias)? } \\
\text { ( ) nunca, ( )às vezes, ( )sempre } \\
\text { 3. Quantas vez foi ao médico no último ano? } \\
\text { 4. Quantas vezes foi ao dentista no último ano? } \\
\text { 5. Alguém já precisou de médico e não conseguiu ser atendido? } \\
\text { ( ) nunca, ( )às vezes, ( )sempre } \\
\text { 6. Alguém da casa já precisou de remédio e você não pôde comprar? } \\
\text { ( ) nunca, ( )às vezes, ( )sempre }\end{array}$ \\
\hline Alimentação & $\begin{array}{l}\text { 1. Quantas refeições você (e sua família) fazem por dia? } \\
\text { 2. O que faz parte de sua alimentação diária: } \\
\text { frutas, legumes, verduras, cereais, carnes, doces, outros. } \\
\text { 3.Já precisou diminuir a quantidade de alimentos por falta de dinheiro? } \\
\text { ( ) nunca, ( )às vezes, ( )sempre }\end{array}$ \\
\hline $\begin{array}{l}\text { Condições de Habitação e Acesso } \\
\text { aos Serviços Básicos }\end{array}$ & $\begin{array}{l}\text { 1.A Sua casa é: própria, alugada ou Cedida é de alvenaria, madeira ou mista } \\
\text { 2.Quantos cômodos têm na casa? } \\
\text { 3.Quantas pessoas moram na casa? } \\
\text { 4. A família possui: geladeira, fogão a gás, TV e rádio, telefone celular, ventilador, ar condicionado, } \\
\text { chuveiro elétrico, liquidificador, computador, outros. } \\
\text { 5.Quantos celulares a família possui? } \\
\text { 6.A família possui: energia elétrica, água encanada/tratada/poço, transporte público na comunidade, } \\
\text { coleta de lixo, internet, drenagem para o esgoto/poço negro, iluminação pública. } \\
\text { 7.As ruas que levam à sua casa são: não asfaltada, parcialmente asfaltada ou plenamente asfaltada. } \\
\text { 8. Existe algum espaço destinado para lazer (atividades para adultos e crianças) no seu bairro? } \\
\text { Como avalia sua condição? Ótima, boa, regular ou péssima. }\end{array}$ \\
\hline Educação & $\begin{array}{l}\text { 1.Você estudou até que série? } \\
\text { 2.Você gostaria de ter estudado mais tempo, mas não teve a oportunidade? O que a impediu? } \\
\text { 3. Alguma pessoa na família é analfabeta (não sabe ler nem escrever)? Quantos? Quem? }\end{array}$ \\
\hline
\end{tabular}

Fonte: Instrumento de pesquisa (2015)

Os resultados da aplicação dos questionários na região nordeste de Santa Maria, bem como sua análise e discussão estão expostos na seção seguinte.

\section{Análise de resultados}

A presente seção tem por objetivo apresentar e discutir os principais resultados do estudo. Optou-se por apresentar os 
resultados no âmbito das dimensões analisadas. Na tabela 01 é possível observar as informações sobre o perfil da população do município de Santa Maria (RS) e da amostra estudada. Conforme dados censitários de 2010 do IBGE e dados oriundos da pesquisa de campo, as mulheres representam 53,06\% da população e 56,03\% da amostra, enquanto o percentual masculino foi de 46,94 para 45,97, respectivamente.

Tabela 1 - Perfil da população de Santa Maria (RS) e da amostra de pesquisa

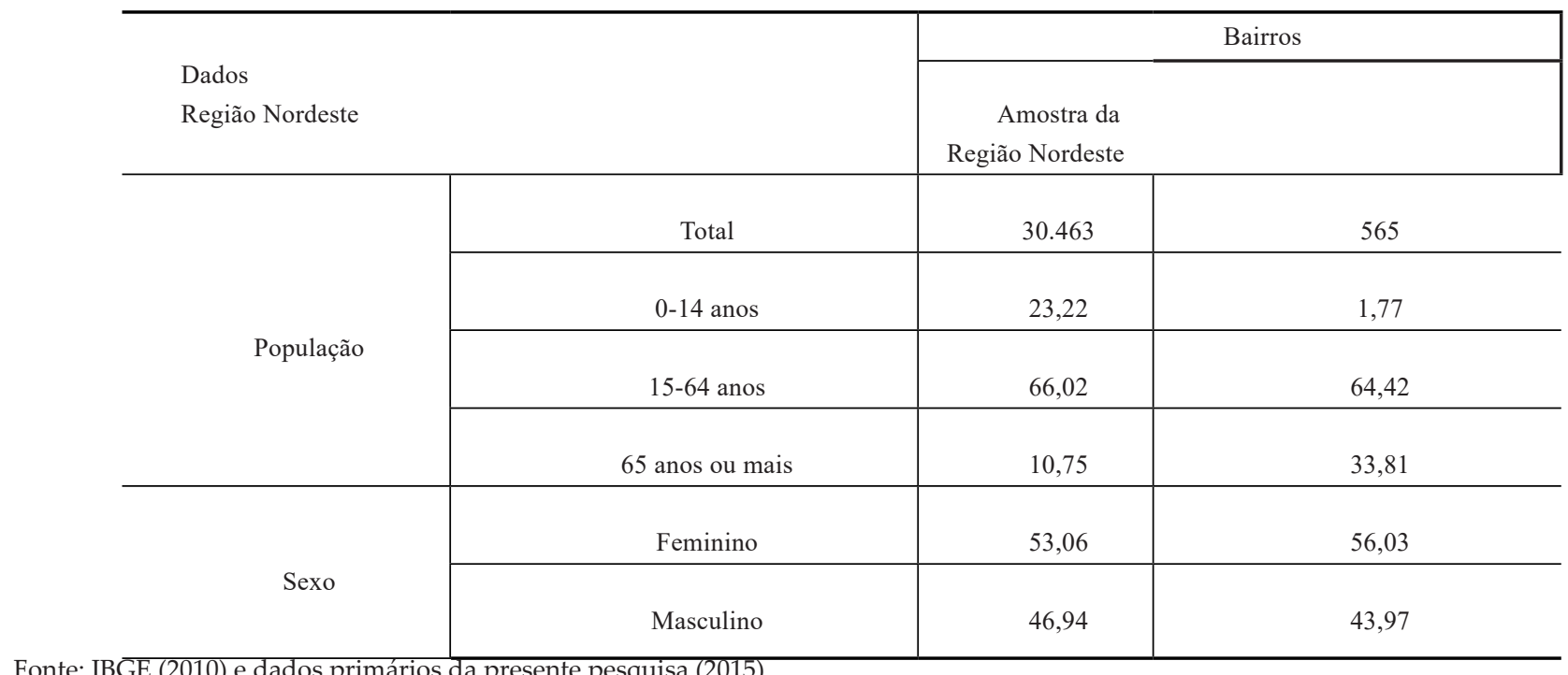

Fonte: IBGE (2010) e dados primários da presente pesquisa (2015).

Em relação à faixa etária, destaca-se que a amostra é composta por indivíduos com idade superior á 12 anos, fato que explica o desvio de $23,22 \%$ da faixa etária populacional. Ao contrário, a população idosa teve um peso maior na amostra quando comparado ao censo. Este resultado pode ser explicado em razão do fato de que as entrevistas ocorreram, em sua grande parte, em dias da semana em horário comercial (segunda à sexta) o que permitiu que a população em não idade escolar e trabalhista estivessem disponíveis para responder à pesquisa. A população em idade ativa (15-64 anos), por sua vez, manteve-se em uma proporção similar aos dados censitários populacionais.

A seguir, apresentam-se os resultados da pesquisa no que se refere às dimensões saúde, alimentação, educação, habitação e acesso aos serviços básicos.

\subsection{Dimensão Saúde}

As condições de saúde é uma das dimensões fundamentais para a conquista do bem-estar social e para a qualidade de vida dos indivíduos. As consequências sobre o bem-estar social do indivíduo, quando este ser é privado do acesso a serviços de saúde, se concretizam sobre o seu trabalho, renda, atividades sociais e também sobre seu estado psicológico.

Wagstaff (2002) afirma que existe uma relação bidirecional entre o fenômeno da pobreza e surgimento de possíveis doenças, uma vez que as enfermidades podem afetar diretamente o rendimento familiar. Indaga-se também, que em países com maior nível de pobreza há maiores ocorrências de diversas doenças. Os indivíduos considerados pobres vêem-se encurralados em um ciclo vicioso; a pobreza é condicionada pelo estado de doença e esta que mantém a pobreza. Além disto, Sen (2010) reitera que o desenvolvimento de uma sociedade dar-se-á pela eliminação das privações de liberdade substanciais que limita as escolhas e oportunidades dos indivíduos.

Portanto, na dimensão saúde, os indivíduos foram indagados sobre suas condições de saúde, sobre o acesso aos serviços básicos de saúde e suas condições financeiras para a compra de remédios. O primeiro questionamento foi sobre o índice de massa corporal (IMC). Segundo a Organização Mundial da Saúde (OMS), pessoas com IMC normal devem estar no intervalo entre 18,5 e 29,9. No entanto, valores menores que 18,5 demonstram desnutrição e índices acima de 29,9 indicam sobrepeso. Deve-se chamar atenção, que o IMC não distingue homens de mulheres. A partir de tais suposições, pode-se observar, na tabela 2 , que mais da metade dos entrevistados $(70,8 \%)$ encontram-se na condição normal do IMC, enquanto que $25,8 \%$ da amostra está na condição de sobrepeso.

Os participantes também foram questionados quanto ao acesso a serviços de saúde, tais como, médicos, dentistas, farmácias, etc. Conforme dados expostos na tabela 02 , para $77,5 \%$ dos respondentes, os serviços de saúde estão plenamente 
acessíveis, enquanto que $17,5 \%$ da amostra afirma que "às vezes" dispõem do acesso a estes serviços. Além disto, somente $5 \%$ dos participantes afirmaram "nunca" terem acesso aos serviços de saúde.

Tabela 2 - Condição de Saúde dos indivíduos participantes da pesquisa na Região Nordeste de Santa Maria (RS)

Índice de Massa Corporal

Número de vezes que foi ao médico

Número de vezes que foi ao dentista

Já precisou de médico e não conseguiu ser atendido

Já precisou de remédio e não pode comprar

\section{Abaixo \\ Normal}

Sobrepeso

Nunca

Às vezes

Sempre

Menos de 2 vezes

Entre 2 e 3 vezes

Mais de 3 vezes

Menos de 1 vezes

Entre 1 e 2 vezes

Mais de 2 vezes

Nunca

Às vezes

Sempre

Nunca

Às vezes

Sempre
$3,4(\%)$

$70,8(\%)$

$25,8(\%)$

$5(\%)$

$17,5(\%)$

$77,5(\%)$

$27,4(\%)$

$37(\%)$

$35,6(\%)$

$32,6(\%)$

$41,2(\%)$

$26,2(\%)$

$74,2(\%)$

$22,1(\%)$

$3,7(\%)$

$73,8(\%)$

$23,2(\%)$

$3(\%)$

Fonte: Dados primários da pesquisa (2016).

Outra questão relevante presente no instrumento de pesquisa, refere-se ao número de vezes que os indivíduos realizaram uma consulta médica. Segundo o parecer do Ministério da Saúde Brasileiro, Portaria 1101/GM de 2002, os indivíduos devem realizar consultas médicas pelo menos 3 vezes ao ano, para assim, conseguirem manter um padrão de vida adequado. Observando os dados compilados da tabela 02 , vê-se que $37 \%$ da amostra analisada realizou entre 2 a 3 consultas ao médico no último ano, porém $35,6 \%$ afirmou que no ano realizou mais de 3 consultas ao médico e apenas $27,4 \%$ dos respondentes realizaram menos de duas consultas médicas no ano.

O número de idas ao dentista também foi um fator de questionamento aos participantes da pesquisa. Segundo a Academia Americana de Odontologia Pediátrica (AAPD), o recomendado é consultar um dentista ao menos duas vezes no ano. Ao ver a tabela 2 , pode-se perceber que $41,2 \%$ dos respondentes realizaram entre 1 a 2 consultas ao dentista no ano. Já 32,6\% da amostra afirmaram terem comparecido menos de 1 vez no ano ao dentista e $26,2 \%$ dos participantes disseram terem realizado mais de duas consultas ao dentista no ano.

Outro questionamento feito aos entrevistados foi quanto ao atendimento médico. A grande maioria (74,2\%) declarou que todas as vezes que se deslocaram ao médico conseguiram atendimento. Já 22,1\% dos respondentes reiteraram que "as vezes" não conseguem atendimento médico e somente $3,7 \%$ da amostra disse não conseguir atendimento médico quando necessita. 
Ademais, também foi indagado aos entrevistados a necessidade da compra de remédios e a disponibilidade de recursos monetários para este fim. A grande maioria da amostra analisada (73,8\%) afirmou que "nunca" tiveram dificuldades em comprar remédios, ou seja, sempre que precisaram realizar a compra de medicamentos conseguiram efetuá-la. Porém, 23,2\% dos entrevistados alegaram que "as vezes" passam por dificuldades na compra de remédios e apenas 3\% dos participantes declararam "sempre" terem dificuldades na aquisição de remédios devido a falta de recursos monetários.

De maneira geral, as condições de saúde dos moradores da região nordeste de Santa Maria/RS são boas, uma vez que tanto o Índice de Massa Corporal (IMC) foi demonstrado ser normal dentre a grande maioria dos moradores, quanto o acesso a serviços de saúde foi considerado pleno (tanto em questões de atendimento médico quanto acesso a medicamentos). As únicas questões deficitárias foi em relação ao número de consultas realizadas no médico e no dentista, do qual ambas as questões não atingiram o número de consultas mínimas exigidas (conforme o parecer do Ministério da Saúde Brasileiro, Portaria 1101/ GM de 2002 e a Academia Americana de Odontologia Pediátrica (AAPD), ou seja, a amostra analisada demonstrou estar em uma situação díspar.

\subsection{Dimensão Alimentação}

As condições de alimentação são avaliadas como determinantes para a situação de pobreza por praticamente todas as abordagens ${ }^{1}$ que discutem tal tema. A alimentação é analisada quando se avaliam as condições de subsistência dos indivíduos, dentro dos aspectos que estimam o atendimento das necessidades básicas dos seres humanos. Segundo Sen (2010, p. 264) “não faltam em nossa época acontecimentos terríveis e abomináveis, mas sem dúvida um dos piores é a persistência da fome para um número imenso de pessoas, em um mundo de prosperidade sem precedentes".

Diante da relevância deste assunto, visou-se observar a situação alimentar da amostra da região nordeste santamariense com perguntas sobre a quantidade, qualidade e diversidade das refeições familiares, assim como a capacitação monetária destes indivíduos de obter alimentos, como pode ser visto na tabela 3.

Tabela 3 - Condições de alimentação dos indivíduos participantes da pesquisa na Região Nordeste de Santa Maria (RS)

\begin{tabular}{|c|c|c|}
\hline \multicolumn{2}{|l|}{ Dados } & Frequência relativa das respostas $(\%)$ \\
\hline \multirow{6}{*}{ Refeições diárias } & 1 & $1,6(\%)$ \\
\hline & 2 & $8,1(\%)$ \\
\hline & 3 & $36,1(\%)$ \\
\hline & 4 & $39,5(\%)$ \\
\hline & $5 \mathrm{ou}+$ & $14,5(\%)$ \\
\hline & Não responderam & $0,2(\%)$ \\
\hline \multirow{4}{*}{ Diversidade de alimentos consumidos diariamente } & Apenas 1 tipo & $1,41(\%)$ \\
\hline & 2 ou 3 tipos & $12,92(\%)$ \\
\hline & 4 ou 5 tipos & $40,89(\%)$ \\
\hline & Todos os tipos listados & $44,78(\%)$ \\
\hline \multirow{4}{*}{$\begin{array}{l}\text { Necessidade de diminuir a quantidade de alimentos por } \\
\text { falta dinheiro }\end{array}$} & Sempre & $2,69(\%)$ \\
\hline & Às vezes & $18,49(\%)$ \\
\hline & Nunca & $78,46(\%)$ \\
\hline & Não responderam & $0,36(\%)$ \\
\hline
\end{tabular}

Fonte: Dados primários da pesquisa (2016).

Quando indagados sobre o número de refeições diárias realizadas, a maior parte da amostra afirmou realizar 3 refeições distribuídas ao correr do dia (café da manhã, almoço e janta). Em 2008, o Ministério da Saúde lançou o "Guia alimentar para população brasileira" que recomenda além das três refeições diárias (café da manhã, almoço e janta) intercalar com pequenos lanches, a fim de garantir o desenvolvimento saudável do corpo. Pode-se afirmar que apenas 14,5\% (5 refeições ou mais) da amostra se alimenta adequadamente, número bem inferior ao esperado. Destaca-se ainda que $9,7 \%$ da população realizam de 1 a 2 refeições indicando alta privação de capacitação para auferir deste bem.

Além disto, buscou-se coletar informações sobre a diversidade das refeições, de forma que o formulário de pesquisa apre-

1 O conceito pobreza de subsistência preocupa-se com fatores meramente físicos para considerar uma pessoa pobre ou não, com foco maior na alimentação (CODES, 2008). O segundo conceito de pobreza é retratado por Crespo e Gurovitz (2002) como sendo as necessidades básicas que uma pessoa deve obter para viver no conjunto individual e familiar: alimentação, vestuário, residência e no conjunto social com acesso aos serviços básicos tais como, saneamento básico, acesso à água potável, instituições de saúde e de educação. 
sentou uma gama de opções com seis tipos de alimentos: fruta, legume, verdura, cereais, carnes e doces, com opção aberta ao entrevistado em citar outros alimentos extras não listados e que também fizessem parte da sua alimentação diária. O Ministério da Saúde enfatiza a necessidade de uma alimentação variada e heterogênea:

A diversidade dietética que fundamenta o conceito de alimentação saudável pressupõe que nenhum alimento específico ou grupo deles isoladamente, é suficiente para fornecer todos os nutrientes necessários a uma boa nutrição e consequente manutenção da saúde (BRASIL, 2008, p. 23).

Quando analisados os dados amostrais, percebe-se que 85,67\% dos respondentes possui diversidade em suas alimentações diárias. Vale salientar ainda que o alimento de menor consumo foram os doces, considerado o alimento de menor significância para aqueles com baixo poder aquisitivo. Outro entrave no consumo deste alimento são os problemas de saúde como, por exemplo, a possível implicação sobre o diabetes.

Além da diversidade da alimentação, para ter-se segurança alimentar, é necessário que todas as pessoas da população tenham permanentemente acesso a alimentos suficientes para uma vida ativa e saudável (HOFFMAN, 1995, p.159). A necessidade de diminuir a quantidade de alimentos por falta de dinheiro em algum momento da vida ocorreu com $21,18 \%$ da amostra da região nordeste de Santa Maria (RS).

Ressalta-se que a situação seria pior se incluídos os respondentes que afirmaram não diminuir a quantidade de alimentos, mas, em contrapartida comprometeram alguma outra capacitação. Este fato é salientado por Brasil (2004), que define e enfatiza que a Segurança Alimentar e Nutricional deve ser uma "realização do direito de todos ao acesso regular e permanente a alimentos de qualidade, em quantidade suficiente, sem comprometer o acesso a outras necessidades essenciais” (BRASIL, 2004, p. 4).

O que pode-se concluir desta dimensão é que a amostra de indivíduos residentes na região Nordeste de Santa Maria não possui alimentação considerada adequada, embora apresente diversidade em sua alimentação diária, apresentou também situação indesejável no número e distribuição das refeições durante o dia. Além disso, a capacitação monetária de auferir deste bem sem comprometer os outros aspectos do bem-estar de uma vida saudável é preocupante uma vez que em torno de $20 \%$ da amostra afirmou passar por este trade off. Os bairros mais deficitários nesta dimensão foram Km Três, Itararé e Campestre do Menino Deus.

\subsection{Dimensão Educação}

Na dimensão educação os entrevistados foram indagados sobre seu nível de instrução educacional, a possibilidade de ter estudado mais tempo e a existência de pessoas analfabetas na família (aquelas que não sabiam ler nem escrever). Quando perguntado aos participantes sobre a quantidade de anos de estudos possuíam, 34,5\% dos respondentes afirmaram ter estudado de 9 a 11 anos, sendo que esse intervalo representa os anos de frequência no ensino médio. Além disso, 27,8\% declararam que possuíam 12 anos ou mais de estudo, ou seja, realizaram ou estão cursando o ensino superior ou pós-graduação. No entanto, $16,6 \%$ da amostra tem apenas 5 anos de estudo, ou seja, afirmaram ter estudado até a $5^{\circ}$ série do ensino fundamental e $21,1 \%$ dos entrevistados admitiram ter entre 6 a 8 anos de estudo, isto é, estudaram da $6^{\circ}$ à $8^{\circ}$ série do ensino fundamental (vide Tabela 4 ).

Tabela 4 - Acesso à educação por parte dos entrevistados residentes na Região Nordeste de Santa Maria (RS)

\begin{tabular}{|c|c|c|}
\hline \multicolumn{2}{|c|}{ Dados } & \multirow{2}{*}{$\begin{array}{c}\text { Frequência relativa das respostas }(\%) \\
16,6(\%)\end{array}$} \\
\hline Anos de Estudo & Até 5 anos & \\
\hline & De 6 a 8 anos & $21,1(\%)$ \\
\hline & De 9 a 11 anos & $34,5(\%)$ \\
\hline & De 12 ou mais anos & $27,8(\%)$ \\
\hline \multirow[t]{3}{*}{ Gostaria de ter estudado mais tempo } & Sim & $69,2(\%)$ \\
\hline & Não & $21,1(\%)$ \\
\hline & Cursando & $9,7(\%)$ \\
\hline \multirow{2}{*}{$\begin{array}{l}\text { Existe alguma pessoa analfabeta na } \\
\text { família }\end{array}$} & Sim & $8,5(\%)$ \\
\hline & Não & $91,5(\%)$ \\
\hline
\end{tabular}

Fonte: Dados primários da pesquisa (2016). 
Os entrevistados também foram questionados sobre a disposição de estudarem mais tempo, e grande parte dos respondentes (69,2\% da amostra) manifestaram-se favoravelmente, porém argumentaram não terem logrado de tal oportunidade devido a fatores como: necessidade de trabalhar para sustentar a família e cuidar dos filhos, difícil acesso à escola, regime social da época impedia que muitas pessoas tivessem acesso à escola, falta de oportunidade, entre outras razões. Porém, 21,1\% dos entrevistados disseram não ter vontade de continuar sua formação educacional e apenas $9,7 \%$ afirmaram ainda estarem estudando.

Os moradores da região nordeste de Santa Maria participantes da pesquisa foram questionados também quanto à existência de algum familiar analfabeto (pessoa que não sabe ler nem escrever). Percebeu-se que 91,5\% dos entrevistados não possui nenhum familiar analfabeto, mas uma pequena percentagem dos respondentes (8,5\%) afirmou ter alguém de seu grupo familiar na situação de analfabetismo. Neste caso, dentre as pessoas da família como analfabetas, estão os avós e os pais.

Portanto, na dimensão educação, pode-se inferir que os moradores da região nordeste de Santa Maria/RS, possuem um grau moderado de escolaridade, uma vez que grande parte terminou o ensino básico. Além do mais demonstrou-se grande interesse, por parte dos participantes da pesquisa, em continuar seus níveis de estudos, uma vez que vislumbravam o ganho econômico e social que esta dimensão pode lhes proporcionar.

\subsection{Dimensão Habitação e Acesso a Serviços Básicos}

A dimensão com maior número de questões é a das condições de moradia e o fornecimento de serviços básicos de utilidade pública. Nesta seção do instrumento de pesquisa, os entrevistados foram convidados a identificar os principais aspectos de suas habitações, disponibilidade de determinados bens e serviços, além de algumas avaliações mais subjetivas. De acordo com Martini (2009):

A definição de necessidades humanas básicas sempre tem algum grau de subjetividade, seja por parte de quem a define para os estudos empíricos, seja social, no sentido de que cada sociedade assume suas próprias necessidades básicas para seus integrantes (MARTINI, 2009. pág.6).

No que diz respeito à composição, os domicílios foram classificados em três categorias: de alvenaria (tijolos, cimento), de madeira, ou misto. Na pesquisa, considera-se que os entrevistados estão residentes em casas de tijolos, vivem em menor grau de privação, uma vez que costumam ser casas mais resistentes, modernas e seguras. Ao passo em que casas de madeira, geralmente mais precárias, oferecem menos segurança e requerem mais cuidados.

A situação observada é positiva. Nota-se a predominância de casas de alvenaria em todos os bairros visitados, cerca de $66,37 \%$ dos entrevistados residiam em domicílios dessa natureza. Imóveis compostos predominantemente de madeira correspondem a $15,57 \%$ da amostra. E casas mistas, compostas de madeira $e$ tijolos, somaram um percentual de $18,05 \%$.

O número de cômodos por domicílio é utilizado como indicador do espaço disponível aos residentes e, portanto, o conforto das instalações. Em situações ótimas, as famílias terão uma baixa concentração de pessoas no espaço. Em situações mais precárias, deve-se observar superlotação. A maioria das residências $(65,30 \%)$ na região nordeste tem mais de cinco cômodos. Embora tal condição não seja suficiente para evitar superlotação, pode-se combiná-la com as informações do número de residentes, a seguir, e obter a densidade por cômodo. A maioria $(92,88 \%)$ das famílias da região nordeste conta com menos de 6 (seis) indivíduos. Casos com mais de seis habitantes em uma mesma residência só se verificaram em $6,8 \%$ da amostra.

Ao combinar as informações do número de habitantes com o número de cômodos, tem-se a densidade por cômodo e a possibilidade de identificar possíveis casos de superlotação capazes de reduzir a qualidade de vida dos residentes. Cerca de $70 \%$ dos entrevistados residem em casas com menos de 0,7 habitantes por cômodo. Logo, afasta-se a possibilidade de admitir superlotação nos domicílios da região. No entanto, é importante frisar que em 17,52\% das residências verifica-se uma relação de mais de 1,1 habitante/cômodo, conforme tabela 5 .

No que se refere ao número de equipamentos disponíveis na casa, verifica-se uma realidade mais homogênea, $75 \%$ da amostra possui entre 7 e 9 dos itens listados no questionário. Isso significa que a maioria dos entrevistados dispõe das comodidades eletroeletrônicas comuns ao cidadão santamariense. Alista inclui dispositivos de comunicação, como rádios e televisores, além de artigos como geladeira, chuveiro, computador, fogão a gás, liquidificador e ar condicionado.

O número de telefones celulares também foi contemplado no instrumento de pesquisa, como indicador da capacidade de comunicação e inserção dos indivíduos na era digital. Em todos os bairros da região nordeste, a maioria dos domicílios (81,23\%) possuía mais de um aparelho de celular.

O número de serviços básicos de utilidade pública com que a população conta é um indicador importante de qualidade de vida. Ao passo que regiões subdesenvolvidas apresentam carência de boa parte dos serviços públicos, regiões com alto padrão de vida costumam dispor de todos, com alta qualidade. Os questionários abordaram sete serviços básicos: fornecimento de energia elétrica, água encanada, transporte público nas cercanias, coleta de lixo, internet, drenagem para esgoto e iluminação pública. 
Tabela 5 - Características da habitação e do acesso a serviços básicos por parte dos residentes na região Nordeste de Santa Maria (RS)

\begin{tabular}{|c|c|c|}
\hline \multicolumn{2}{|c|}{ Dados } & \multirow{2}{*}{$\begin{array}{l}\text { Frequência relativa das respostas (\%) } \\
\qquad 76,10(\%)\end{array}$} \\
\hline Tipo de imóvel & Próprio & \\
\hline & Alugado & $20,00(\%)$ \\
\hline & Cedido & $3,89(\%)$ \\
\hline \multirow[t]{3}{*}{ Material da casa } & Alvenaria & $66,37(\%)$ \\
\hline & Madeira & $15,57(\%)$ \\
\hline & Mista & $18,05(\%)$ \\
\hline \multirow[t]{6}{*}{ Densidade por cômodo } & Até 0,3 & $20,88(\%)$ \\
\hline & 0,3 a 0,5 & $34,33(\%)$ \\
\hline & 0,5 a 0,7 & $15,57(\%)$ \\
\hline & 0,7 a 0,9 & 7,78 (\%) \\
\hline & 0,9 a 1,1 & $3,89(\%)$ \\
\hline & Mais de 1,1 & $17,52(\%)$ \\
\hline \multirow[t]{3}{*}{ Número de equipamentos } & Até 4 & $0,70(\%)$ \\
\hline & De 5 a 8 & $42,30(\%)$ \\
\hline & De 9 a 12 & $56,99(\%)$ \\
\hline \multirow[t]{6}{*}{ Número de telefones celulares } & 0 a 1 & $18,76(\%)$ \\
\hline & 2 & $27,61(\%)$ \\
\hline & 3 & $28,14(\%)$ \\
\hline & 4 & $15,92(\%)$ \\
\hline & 5 & $5,13(\%)$ \\
\hline & 6 ou mais & $4,42(\%)$ \\
\hline \multirow[t]{4}{*}{ Número de serviços básicos } & Até 4 & $4,77(\%)$ \\
\hline & 5 & $12,56(\%)$ \\
\hline & 6 & $31,32(\%)$ \\
\hline & 7 & $51,32(\%)$ \\
\hline \multirow[t]{3}{*}{ As ruas são asfaltadas? } & Não & $35,75(\%)$ \\
\hline & Parcialmente & $32,92(\%)$ \\
\hline & Sim & $31,32(\%)$ \\
\hline \multirow[t]{2}{*}{ Espaços de lazer } & Sim & 40,88 (\%) \\
\hline & Não & $59,11(\%)$ \\
\hline \multirow[t]{4}{*}{ Condições dos espaços de lazer } & Ótimas & $14,89(\%)$ \\
\hline & Boas & $31,48(\%)$ \\
\hline & Regulares & $25,53(\%)$ \\
\hline & Péssimas & $28,08(\%)$ \\
\hline
\end{tabular}

Fonte: Dados primários da pesquisa (2016)

A maioria dos domicílios da região possuía mais de 5 (cinco) dos serviços básicos. Conexão com a internet e drenagem para esgoto foram os dois itens que se apresentaram com menor frequência ao longo da pesquisa. Em casos onde a drenagem de esgoto não se verificava, os domicílios contavam com poço negro. No caso da internet, a baixa presença pode se dar em virtude de tratar-se de uma região com grande quantidade de idosos e aposentados, com nenhuma atividade escolar ou profissional em andamento.

A presença de ruas asfaltadas nos bairros permite compreender a viabilidade da circulação de veículos de transporte, público e particular, a serviço dos moradores. Os entrevistados foram solicitados a responder se as ruas próximas às suas casas eram asfaltadas. Como opções de resposta: "não"; "parcialmente"; e "completamente".

A questão do asfaltamento das ruas é, provavelmente, a de maior heterogeneidade de respostas dentro da dimensão de Habitação/Serviços Básicos. Os diferentes bairros da região nordeste de Santa Maria apresentam uma considerável diferença nesse quesito. Cerca de 35,75\% dos entrevistados responderam que "não", 32,92\% "parcialmente" e 31,32\% "sim". De toda forma, pode-se perceber que as ruas da região nordeste de Santa Maria ainda carecem de amplos in- 
vestimentos em pavimentação para garantir aos moradores uma maior qualidade de acesso e utilização dos meios de transporte.

A dimensão Habitação/Serviços Básicos também compreende a infraestrutura dedicada ao lazer nos diferentes bairros. Na abordagem utilizada pela pesquisa, encara-se o lazer como uma oportunidade de inserção na vida comunitária, uma vez que costuma envolver interações significativas com outros indivíduos, seja pela prática esportiva, ou demais práticas de socialização. Quanto à importância do lazer para os jovens, o UN World Youth Report (2003, p. 2) afirma que:

It is imperative that youth be given a wide range of opportunities for meaningful participation within the community, provided or facilitated by a multitude of organizations, institutions and programmes in all sectors. (UN WORLD YOUTH REPORT; 2003, p. 2)

À luz de tais considerações, torna-se importante verificar a existência de espaços adequados para lazer nos bairros. De acordo com os resultados obtidos pela aplicação do instrumento de pesquisa, há uma grande diversidade no acesso ao lazer, dentre os diferentes pontos da região nordeste de Santa Maria, 40,88\% dos moradores da região disseram contar com espaços de lazer nas proximidades de suas residências. Por outro lado, os outros 59,11\% não contam com a mesma sorte.

Uma vez identificada a existência ou inexistência, de espaços de lazer nos diferentes bairros da região, o instrumento de pesquisa continha uma última questão a respeito das condições de conservação do referido espaço de lazer. Dentre os quase quarenta por cento que disseram morar próximos a espaços de lazer, 14,89\% disseram que as condições eram ótimas. Outros $31,48 \%$ apontaram que eram boas, $25,53 \%$ regulares e $28,08 \%$ péssimas.

Observa-se uma grande diversidade de respostas entre os entrevistados. Isso indica que alguns bairros possuem estrutura de lazer superior à dos demais. Ou, alternativamente, que os indivíduos entrevistados tenham opiniões divergentes sobre a presença e importância dos espaços de lazer dos mesmos bairros.

\section{Considerações finais}

No presente trabalho realizou-se um estudo a respeito da pobreza multidimensional na região Nordeste da cidade de Santa Maria (RS), que compreende os seguintes bairros: KM Três, Presidente João Goulart, Itararé, Nossa Senhora das Dores, Menino Jesus e Campestre do Menino Deus. O instrumento com a coleta de dados primários compreendia uma série de perguntas que abordaram dimensões como educação, saúde, habitação e serviços básicos. De forma geral, as pessoas entrevistadas apresentaram um baixo nível de pobreza multidimensional, porém com alguns indícios de privação em certas dimensões, como o acesso a certos serviços e melhorias, justificado pela falta de investimentos públicos.

Respondendo o problema de pesquisa, os moradores da região não relataram dificuldade no acesso a maioria dos serviços, porém, ainda enfrentam alguns empecilhos no que se refere a aquisição via renda. Ao que se refere à dimensão Saúde, a amostra não apresentou indícios de privação com a alimentação, porém possui situação indesejável no número e distribuição dessas refeições, além de a disponibilidade de renda comprometer a aquisição dos alimentos. Em relação à dimensão Educação, percebe-se que grande parte da amostra possui acesso ao ensino, além de apresentar poucos casos de analfabetismo na família. Em relação à dimensão habitação e serviços básicos, os habitantes apresentam grande diversidade de respostas no que se refere as estruturas dos bairros.

Pode-se concluir que a pobreza multidimensional aponta se há privação ou não sofrida pelos indivíduos em cada uma das dimensões elencadas para análise. Salienta-se também que a definição das dimensões, indicadores e limites utilizados no formulário de pesquisa, foram selecionadas a partir de uma vasta pesquisa de revisão bibliográfica, em sites especializados, órgãos públicos e opiniões de especialista, a fim de captar os indicadores que melhor indicariam a realidade econômica e social da cidade de Santa Maria RS, de acordo com características particulares da cidade.

\section{Referências}

AAPD. Academia Americana de Odontologia Pediátrica. Disponível em <http://www.aapd. org/>. Acesso em 22 de abril de 2017.

BARROS, R. P.; HENRIQUES, R.; MENDONÇA, R.. A Estabilidade inaceitável: desigualdade e Pobreza no Brasil. IPEA, Textos para discussão n. 800, jun. 2001, 24p.

BRASIL. Conselho de Segurança Alimentar e Nutricional (Consea). Princípios e diretrizes de uma Política de Segurança Alimentar e Nutricional. In: CONFERÊNCIA NACIONAL DE SEGURANÇA ALIMENTAR E 
NUTRICIONAL, 2., 2004, Olinda. Brasília: Consea, 2004a. 80 p.

BRASIL. Ministério da Saúde. Secretaria de Atenção à Saúde. Coordenação-Geral da Política de Alimentação e Nutrição. Guia alimentar para a população brasileira: promovendo a alimentação saudável. Brasília: Ministério da Saúde; 2008

CODES, A. L. M. A Trajetória do Pensamento Científico Sobre Pobreza: Em direção a uma visão complexa. Brasília: IPEA, 2008. (Textos para discussão n⿳ำ 1332)

CRESPO, A. P. A.; GUROVITZ, E. A Pobreza como um Fenômeno Multidimensional. RAE - Eletrônica, v. 1, n.2, p. 1-12, 2002.

IBGE - Instituto Brasileiro de Geografia e Estatística. Disponível em: <http://www.ibge.gov.br>, acesso em 18 de abril de 2017.

HOFFMANN, R. Pobreza, insegurança alimentar e desnutrição no Brasil. Estudos Avançados, v.9 n.24, p.159172. São Paulo: Instituto de Estudos Avançados da Universidade de São Paulo, maio/agosto de 1995.

MARTINI, R.A. Um Ensaio Sobre os Aspectos Teóricos e Metodológicos da Economia da Pobreza. Belo Horizonte: UFMG/Cedeplar, 2009. (Texto para Discussão no 369).

MINISTÉRIO DA SAÚDE. Gabinete do Ministro. Portaria GM, n.1101, 2002. Disponível em http://portalsaude. saude.gov.br/. Acesso em 22 de abril de 2017

OMS. Organização Mundial da Saúde. Disponível em: http://www.who.int/eportuguese/publications/pt/. Acesso em 22 de abril de 2017.

ORGANIZAÇÃO DAS NAÇÕES UNIDAS. UN World Youth Report. Nova Iorque. 2003. Disponível em: <http:// www.un.org/esa/socdev/unyin/documents/worldyouthreport.pdf> Acessado em: 04/04/2017.

ROQUE, A. Desenvolvimento como liberdade: uma aplicação dos conceitos de Amartya Sen à educação de adultos. 2009. 153f. Dissertação (Mestrado em Administração de Empresas) - Centro Universitário da FEI, São Paulo, 2009.

SEN, A. Desenvolvimento como liberdade. Companhia das Letras, São Paulo, 2010

UNITED NATIONS. World Youth Report 2003. Disponível em: <http://www.un.org/esa/socdev/unyin/ documents/worldyouthreport.pdf> (acessado em 04/04/2017)

WAGSTAFF. A. Pobreza y desigualdades en el sector de la salud. Pan American Journal of Public Health 11(56):316-326, 2002. 